\title{
DAMPAK KRISIS EKONOMI YUNANI TERHADAP EUROPEAN ECONOMIC COMMUNITY (EEC)
}

\author{
Nur Inna Alfiyah ${ }^{1}$ \\ Very Andrianingsih ${ }^{2}$ \\ ${ }^{1}$ FISIP Universitas Wiraraja, Indonesia \\ ${ }^{1}$ nurinna@wiraraja.ac.id \\ ${ }^{2}$ FEB Universitas Wiraraja, Indonesia \\ 2 veryandrianingsih@wiraraja.ac.id
}

\begin{abstract}
Globalization is a phenomenon that cannot be separated from human life, where all international structures and orders change. Easy access to information, technology and the exchange of goods, services and ideology make globalization a very important part. Changing the structure and economic, political and social order at this time requires existing countries to adapt to all changes brought about by globalization. The birth of non-state actors in globalization then brought about its own changes, especially in the economic field. This study aims to explain how the impact of the Greek economic crisis on the European economic community. The method used in this research is a qualitative method with a descriptive approach. The results of this study indicate that the economic interdependence between European countries which has led to the birth of the European Economic Community (EEC) is very influential on one another. This can be seen from how the Greek crisis was able to change the economic policy order of member countries of the European Economic Community (EEC).
\end{abstract}

Keywords : Interdependensi, European Economic Community (EEC), Greek Crisis

\section{PENDAHULUAN}

Dalam era globalisasi saat sekarang hubungan antar negara baik di bidang sosial, politik dan ekonomi tidak bisa dihindari karena tiap negara pasti akan melakukan hubungan bilateral maupun multilateral. Salah satu hubungan yang esensial sekali untuk setiap negara lakukan adalah pada hubungan ekonomi. Karena dengan melakukan kerjasama bidang ekonomi akan mampu menentukan maju atau tidaknya perekonomian suatu Negara. Dengan kata lain proses hubungan antar negara dalam bidang ekonomi dengan tujuan menyatukan ekonomi antar negara di dunia disebut dengan globalisasi ekonomi. Globalisasi yang didentikkan dengan mengaburnya batas negara (borderless) kemudian menjadi sangat berdampak bagi berubahnya perekonomian dunia. Dampak dari globalisasi terhadap ekonomi tersebut mengharuskan negara-negara di dunia untuk menghapuskan batas serta halangan pada aliran dana, barang dan jasa. Globalisasi pada bidang ekonomi ini dapat dilihat dari integrasi ekonomi yang mampu melintasi batas wilayah nasional negara-negara yang ada di dunia. Hal ini berimabas pada aliran keuangan yang masuk, investasi asing 


\section{FAKULTAS EKONOMI DAN BISNIS UNIVERSITAS WIRARAJA - MADURA}

langsung (foreign direct investment)

melalui perusahaan-perusahaan

multinasional kemudian melahirkan

bentuk interdependensi yang semakin

aktif (Steger, 2002). R.J. Barry Jones

menerangkan dalam bukunya bahwa

"interdependence exists for a set of two

or more actors when each is dependent upon one other member of that set for satisfactory outcomes on any issue(s) of concern" (Barry Jones, 2013). Sehingga bisa dikatakan bahwa interdependensi adalah ketergantungan yang timbal balik, dimana bisa di ilustrasikan ketika A membutuhkan B, dan B membutuhkan A. Ini juga bisa dilihat bagaimana interdependensi yang dilakukan oleh negara, karena tiap negara pasti memiliki kekurangan dalam hal resources sehingga pasti membutuhkan negara lain untuk memasok produk yang dibutuhkan. Dari sinilah kemudian muncul interdependensi ekonomi dari tiap negara.

Adanya interdependensi kemudian melahirkan perdagangan bebas yang memiliki definisi dimana perdagangan tersebut dilakukan tanpa adanya hambatan. Perdagangan tanpa hambatan ini biasnya berdasar pada kebijkan pemerintah masing-masing negara dengan tidak mendiskriminasi perdagangan baik impor maupun ekspor. Dihapuskannya batasan dan halangan terhadap aliran modal, barang dan jasa akan memberikan peluang bagi produk dalam negeri suatu negara untuk menembus pasar internasional. Lahirnya perdagangan bebas kemudian memunculkan aktor-aktor non negara seperti perusahaan multinasional, yang pada saat ini menjadi salah satu aktor penting dalam perekonomian dunia. Pada umumnya adanya perusahaanperusahaan multinasional yang ada dapat memberikan manfaat bagi negaranegara sedang berkembang, dimana dengan adanya perusahaan multinasional disuatu negara akan menciptakan lapangan kerja bagi masayarakat negara tersebut. Meskipun dalam beberapa hal banyak pendapat yang pesimis dengan adanya globalisasi yang menguntungkan bagi negara berkembang. Karena para pesimis tersebut melihat hingga saat ini perkembangan negara berkembang sangat jauh berbeda dari negara maju yang dapat dilihat dari peerkembangan pembangunan ekonomi, pendidikan dan lainnya. Terciptanya pasar bebas memberikan kesempatan bagi negara berkembang untuk mengejar ekonomi negara maju, dimana untuk mengejar ekonomi negara maju tersebut bergantung dari starategi serta cara yang dilakukan oleh negara berkembang. Sehingga dengan starategi tersebut dapat mampu mendatangkan keuntungan bagi negaranya. 
Diatas telah dijelaskan bahwa interdependensi merupakan hubungan saling kebergantungan antar negara satu dengan negara lain, ketergantungan antara negara satu dengan lain ini kemudian mendorong lahirnya komunitas ekonomi untuk semakin memperlancar hubungan antar negara. Pasca perang dunia I dan II, Robert Schuman yang merupakan mentri luar negeri Perancis pada saat itu mengemukakan sebuah gagasan tentang pembentukan sebuah organisasi yang akan mampu menyelamtkan Eropa di masa depan. Gagasan tersebut tertuang dengan terbentuknya "European Coal and Steel Community (ECSC)" pada tanggal tanggal 18 April 1951 (The Editors of Encyclopaedia Britannica, 2016). Tujuan utama ECSC Treaty adalah penghapusan berbagai hambatan perdagangan dan menciptakan suatu pasar bersama dimana produk, pekerja dan modal dari sektor batu bara dan baja dari negara-negara anggotanya dapat bergerak dengan bebas. ECSC yang dibentuk oleh 6 negara pionir yang juga merupakan anggota Dewan Eropa yaitu Perancis, Jerman, Belgia, Belanda, Luxemburg dan Italia terbukti setelah lebih dari setengah abad, berhasil menyatukan Eropa secara politik dan ekonomi sekaligus meningkatkan martabat negara-negara Eropa. Sehingga peperangan anatar negara Eropa bisa terhindari dengan adanya integrasi negara-negara Eropa.

Seiring berkembangnya waktu ECSC kemudian berkembang menjadi European Economic Community (EEC) sebagai hasil dari perjanjian Roma. Tujuan pembentukan EEC adalah, pertama untuk mengintegrasikan Eropa dengan cara bekerjasama pada bidang ekonomi, peningkatan jaminan hidup serta perluasan kesemoatan kerja bagi masing-masing negara anggota. Kedua, peningkatan perdagangan antar negara dan penciptaan pasar bebas serta keseimbangan perdagangan antar negara anggota. Ketiga, dihapuskannya nya semua barrier yang menghambat laju perdagangan internasional dan meluaskan hubungan dengan negaranegara selain anggota EEC. Untuk mewujudkan tujuannya, EEC membentuk common market, keseragaman tarif, serta kebebasan dalam hal kebijakan buruh, barang, serta modal (Rizka, 2013).

Terbentuknya Masyarakat Ekonomi Eropa kemudian menarik minat negara-negara Eropa yang lain untuk masuk menjadi anggota MEE, yang kemudian berkembang menjadi semakin luas dengan terbentuknya Uni Eropa. Interdependensi ekonomi yang terjadi kemudian semakin intens, dimana antara negara satu dan yang lain saling terikat dan saling mempengaruhi. 
Ditetapkannya Euro sebagai mata uang tunggal dapat meningkatkan efisiensi ekonomi begi negara-negara penggunanya, seperti mempermudah perdagangan antar negara, suku bunga yang satabil dan lainnya. Meskipun beberapa negara di Eropa masih ada yang belum menetapkan Euro sebagai mata uang negaranya seperti Inggris yang masih menggunakan Poundsterling. Saling kebergantungan antara negara Eropa dapat terlihat ketika terjadi krisis ekonomi yang terjadi di Yunani, dimana dampak dari krisis tersebut dirasakan oleh negara Eropa yang lain.

\section{METODE}

Pada penelitian ini, peneliti menggunakan metode deskriptif kualitatif dimana peneliti mendapatkan hasil penelitian dengan melakukan pengumpulan data dari buku, jurnal, laporan penelitian, berita dan website resmi, ditunjang dengan wawancara sesuai dengan informan penelitian sebagai bentuk analisis data komprehensif terkait dampak krisis ekonomi Yunani terhadap European Economic Comunity (EEC).

\section{HASIL PENELITIAN}

Pada tahun 2007, krisis finansial yang dimulai di AS dengan cepat merambah dimensi global dengan mempengaruhi banyak negara maju dan berkembang. Dampak krisis khususnya lebih dalam dan merusak di beberapa negara. Yunani juga termasuk di antara negara-negara ini. Krisis Yunani pada dasarnya tidak disebabkan langsung oleh krisis finansial yang terjadi di AS, melainkan krisis terjadi jauh sebelumnya. Hal ini dapat dilihat dari krisis keungan dalam negari yang meningkatkan hutang publik. Yunani resmi bergabung dengan Uni Eropa pada tahun 1981. Setelah tergabung dalam Uni Eropa, seluruh kebijakan ekonomi dan politik Yunani akan bersinggungan dengan kehidupan ekonomi dan politik kawasan, terutama dalam hal ekonomi sejak Yunani bergabung dalam Eurozone pada tahun 2001. Yunani menggunakan euro menggantikan drachma (Simanjuntak \& Wijanarka, 2016).

Bisa dikatakan bahwa situasi Yunani saat ini adalah akibat dari kebijakan yang salah yang diterapkan dalam 25-30 tahun terakhir. Proses ini terkait erat dengan pemborosan keuangan dan ketidakcukupan pemerintahan Yunani, sistem perpajakan yang tidak adil dan tidak subur, pensiun yang tidak berkelanjutan, daya kompetitif yang rendah, praktik populis partai politik dan masalah organisasi dan politik di UE dan Zona Euro (Ozturk \& Sozdemir, 2015).

Selama bertahun-tahun, Yunani berhasil mengontrak hutang dengan 
suku bunga rendah dengan bermain pada indikator ekonomi dasar berkat dukungan akuntansi yang diberikan oleh Goldman Sachs. Jika proses sebelum krisis menjadi pertimbangan, terlihat bahwa tingkat utang Yunani terhadap PDB-nya adalah salah satu yang tertinggi di Eropa. Angka ini terutama meningkat setelah tahun 2000 dan melampaui $160 \%$ dan jauh melampaui kriteria (60\% dari PDB). Jika dibandingkan dengan Spanyol, Portugis, Italia, dan Irlandia, situasinya dapat dilihat dengan jelas (Grafik 1). Elemen yang paling menarik perhatian yang memicu sumbu krisis adalah pendekatan dan pernyataan pemerintah yang meningkatkan ketidakpastian dan kekhawatiran tentang rendahnya keandalan statistik keuangan dan sejauh mana masalah keuangan yang sebenarnya dan kemungkinan keuangannya. Dapat dikatakan bahwa negara-negara Uni Eropa terlambat membaca indikator dan gagal mendukung Yunani karena krisis yang meningkat di negara tersebut (Ozturk \& Sozdemir, 2015).

Yunani bisa dikatakan mengalami masalah jauh sebelum krisis global dimulai. Tanpa disadari pemicu dari krisis Yunani sendiri bersumber dari pemborosan uang karena praktek- praktek yang menyebabkan kemerosotan ekonomi dan sosial seperti penyuapan, korupsi yang menyebabkan defisit anggaran tingkat tinggi, utang publik yang meningkat pesat, defisiensi belanja investasi dan ketidakseimbangan akutansi yang dilakukaan oleh Yunani. Efek domino dari krisis Yunani kemudian menulari negara-nagara Eropa yang lain seperti Spanyol, Irlandia, Siprus, Islandia serta Itali. Dampak efek domino tersebut dapat terlihat ketika negara-negara Eropa ekonominya terdampak hingga berpotensi mengalami krisis di dalam negarinya. Sehingga isu ini kemudian mejadi isu panas yang memerlukan solusi cepat dari anggota Uni Eropa agar tidak semakin parah dampaknya.

Impact yang ditimbulkan oleh krisis ekonomi Yunani terhadap negaranegara eropa lain dapat dilihat sebagai sebuah interdependensi yang kompleks. Meskipun krisis tersebut terjadi di Yunani dampaknya dapat dirasakan oleh negara Eropa lain, karena terganggunya aktifitas ekonomi di Yunani kemudian mempengaruhi aktifitas ekonomi yang lain. Disinilah bentuk interdependensi yang terjadi, dimana ketika negara yang satu dan negara yang lain saling bergantung maka ketika terjadi sebuah masalah maka dampaknya juga kan dirasakan oleh yang lain. 


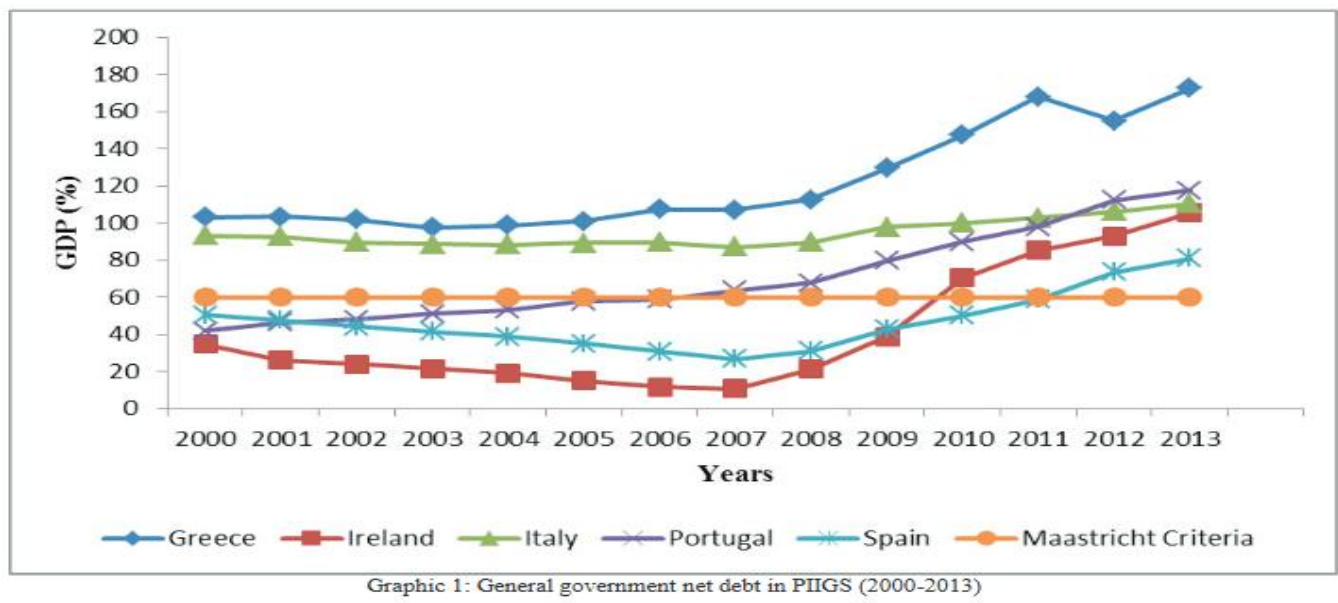

Istilah domino adalah salah satu fenomena berubahnya geo-politik serta geo-strategi yang terjadi secara beruntun. Hal mendasar yang menjadi kunci dari krisisi Yunani terjadi adalah adanya ketidakmampuan pemerintah dalam melunasi utang yang menumpuk hingga keuangnnya mencapai defisit. Ketidakmampuan pemerintah dalam mengatasi krisis keuangan tersebut berdampak pada tidak stabilnya nilai Euro yang kemudian berimbas pada negara-negara lain di kawasan Eropa lain seperti Portugal, Italia, Irlandia, Spanyol, dan beberapa negara lain yang juga memiliki masalah utang negara sendiri.

Dampak krisis ini dirasakan oleh Irlandia dengan meningkatnya utang negara yang bersangkutan hingga $123,30 \%$. Sedangakan utang Pemerintah Portugal terakhir dilaporkan pada $93 \%$ dari PDB negara itu. Dari tahun 19902010, rata-rata utang pemerintah
Portugal terhadap PDB adalah 60,32\%. Di Spanyol dampak dari krisis Yunani ditandai dengan resesi menurunnya pertumbuhan ekonomi. Penurunan sektor kontruksi dengan signifikan di tengah tingginya pasokan perumahan dan anjloknya belanja konsumen Akbatnya utang negara tersebut dilaporkan naik hingga 92,1\% dari PDB negara. Di Italia, krisis dirasakan dengan meningkatnya utang pemerintah akibat anjloknya euro hingga menembus angka $119 \%$ dari PDB negara. Hutang yang tinggi ini kemudian berpengaruh buruk pada sektor dalam negara Itali, khususnya pada terhambatnya laju pertumbuhan ekonomi (Hananaomi, 2015). Dampak paling besar dari krisis Yunani yang dirasakan oleh negaranegara terdampak adalah meningkatnya kemiskinan dan pengangguran hingga signifikan. Di Yunani sendiri tingkat kemiskinan pada wal krisis antara tahun 2007 hingga 2010 mencapai $20 \%$. 
Dampak sosial lainnya adalah dengan meningkatnya angka bunuh diri sampai $36 \%$. Upaya untuk mnegatasi krisis yang terjadi di Yuanani sendiri banyak dilakukan oleh pemerintah Yunani salah satunya dengan menegosiasikan jumlah hutan negara mereka ke negara anggota Uni Eropa. Kesepakatan ini dikenal dengan European Debt Conference yang bertujuan untuk meringankan jumlah hutang yang dimiliki oleh Yunani (Daniel, 2020). Pada tahun 2018, Yunani berhasil keluar dari tiga dana talangan sehingga pemerintah Yunani dan IMF memprediksi pada tahun berkutnya Yunani akan terlepas dari krisis. Karena selama krisis pertama kalinya ekonomi Yunani tumbuh hingga 1,9\% (Perwitasari, 2020). Dalam rangka memper tahankan trend positif dari perekonomian negara. karena pada 2020 saat pandemi melanda otomatis akan berdampak pada macetnya sektor wisata yang menjadi kontribusi terbesar pendapatan Yunani. Sehingga untuk tetap mempertahankan performa pertumbuhan laju ekonomi positif Yunani diperlukan langkah-langkah kebiajakan signifikan dari pemerintah pembuat kebijakan.

\section{KESIMPULAN DAN SARAN}

Interdependensi yang terjadi

$\begin{array}{llr}\text { diantara negara-negara } & \text { Eropa } \\ \text { memanglah sangat riskan. Hal ini } \\ \text { dikarenakan dapat memicu kerugian } \\ \text { bagi negara-negara anggota lain jika }\end{array}$

salah satu anggota negara tersebut mengalami resesi atau krisis. Seperti yang terjadi ketika Yunani dilanda krisis moneter menyebabkan negara lain seperti Italia, Spanyol dan lainnya juga terkena imbas akibat melemahnya euro dan macetnya pertumbuhan ekonomi yang kemudian berdampak pada tingginya rasio hutang terhadap PDB, serta terperangkap oleh defisit anggaran yang tinggi dalam membiayai sektor publik. Sehingga untuk meminimalisir dampak dari interdependensi akibat krisis ekonomi yang terjadi di Uni Eropa dibutuhkan kebijakan ekonomi yang matang di tiap negara serta management keuangan serta beanja negara yang efektif agar tidak terkena imbas dari krisis ekonomi.

\section{DAFTAR PUSTAKA}

Barry Jones, R. J. (2013). Globalization and Interdependence In The International Political Economy. Bloomsbury Academic.

Daniel, C. (2020). Dampak Krisis Yunani terhadap Sistem Integrasi di Eropa - Kompasiana. Komps.

Hananaomi, F. (2015). Dampak Domino Krisis Eurozone Terhadap Negara Italia. Jurnal Online Mahasiswa FISIP Universitas Riau, 2(1), 113. https://media.neliti.com/media/pub lications/31971-ID-dampakdomino-krisis-eurozone-terhadapnegara-italia.pdf 
FAKULTAS EKONOMI DAN BISNIS UNIVERSITAS WIRARAJA - MADURA

Ozturk, S., \& Sozdemir, A. (2015). Effects of Global Financial Crisis on Greece Economy. Procedia Economics and Finance, 23(October 2014), 568-575. https://doi.org/10.1016/s22125671(15)00441-4

Perwitasari, A. S. (2020). Yunani memperkirakan pertumbuhan ekonomi 2020 menyusut antara 5\% hingga 10\%. Kontan.co.id. https://internasional.kontan.co.id/n ews/yunani-memperkirakanpertumbuhan-ekonomi-2020menyusut-antara-5-hingga-10
Rizka, E. (2013). Masyarakat Ekonomi Eropa (MEE). http://www.scribd.com/doc/560524 66/MEE-Masyarakat-EkonomiEropa

Simanjuntak, T. R., \& Wijanarka, T. (2016). Masa Depan Uni Eropa Setelah Krisis Yunani. Cakrawala, 5(1), 1-28.

Steger, M. B. (2002). Globalism, The New Market Ideology. Lafadl Pustaka.

The Editors of Encyclopaedia Britannica. (2016). European Coal and Steel Community | European organization | Britannica. In Encyclopeadia Britannica. https://www.britannica.com/topic/ European-Coal-and-SteelCommunity 